UDC 631.67:255

LBC 40.62

\title{
ASSESSMENT AND METHOD OF WATER RESOURCES MANAGEMENT IN THE ASA RIVER BASIN
}

Balzhan Sh. Amanbayeva

Kazakh National Agrarian Research University, Almaty, Kazakhstan

Ermekkul D. Zhaparkulova

Kazakh National Agrarian Research University, Almaty, Kazakhstan

Mustafa G. Mustafayev

Institute of Soil Science and Agrochemistry of Azerbaijan National Academy of Science, Baku, Azerbaijan

\section{Jozef Mosiej}

Warsaw University of Life Sciences - SGGW, Warsaw, Poland

\begin{abstract}
ָิ
Abstract. The article presents the method of water resources management in the Asa river basin and indicators

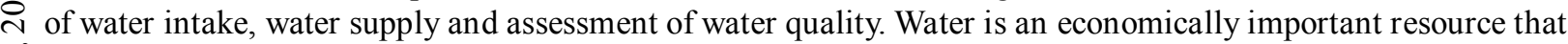
$\tilde{\sim}$ determines the sustainability of a country's development. New trends show that water issues are becoming more complex with other sectors, including agriculture, energy, industry, transport, and communications, as well as with डै social sectors: education, environment, and healthcare, rural or regional development. The rational use of water $\sum^{2}$ resources, as well as the protection of water resources and access to drinking water are an important priority for the

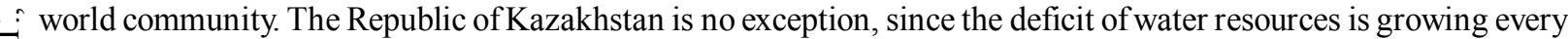
year. Today's global challenges, especially climate change and population growth, are making the situation even more worrisome. Climate change is caused by dynamic processes on Earth, external influences such as fluctuations in the intensity of sunlight, and recent human activities. Consequently, in the conditions of Kazakhstan, where water resources are limited, and irrigation develops in various natural and climatic zones, further intensification of irrigated agriculture can be carried out through the development of environmentally friendly integrated technologies, ecological $\therefore$ and reclamation management of water and land resources, ensuring a decrease in the amount of unproductive losses Ii of irrigation water, as well as protection of water and land resources from pollution by collector-waste waters, leaching $\tilde{0}$ of organic substances and nutrients, the rate of salt accumulation in the root layer and the rate of alkalization and alkalinization processes. This approach is predetermined by the fact that the existing methods of water resources management inevitably lead to large losses of irrigation water for infiltration, discharge and evaporation, the value of which reaches $60-70 \%$ of the water intake.
\end{abstract}

Key words: water resources, water intake, groundwater, water saving technology, irrigation, surface water.

Citation. Amanbayeva B.S., Zhaparkulova E.D., Mustafayev M.G., Mosiej J. Assessment and Method of Water Resources Management in the Asa River Basin. Prirodnye sistemy i resursy [Natural Systems and Resources], 2021, vol. 11, no. 2, pp. 49-55. DOI: https://doi.org/10.15688/nsr.jvolsu.2021.2.6 
УДК 631.67:255

ББК 40.62

\title{
ОЦЕНКА И МЕТОД УПРАВЛЕНИЯ ВОДНЫМИ РЕСУ РСАМИ В БАССЕЙНЕ РЕКИ АСА
}

\author{
Балжан Шакировна Аманбаева \\ Казахский национальный аграрный университет, г. Алматы, Казахстан \\ Ермеккуль Дукеновна Жапаркулова \\ Казахский национальный аграрный университет, г. Алматы, Казахстан \\ Мустафа Гылман Мустафаев \\ Институт почвоведения и агрохимии НАН Азербайджана, г. Баку, Азербайджан \\ Джозеф Мосиеж \\ Варшавский университет естественных наук, г. Варшава, Польша
}

\begin{abstract}
Аннотация. В статье представлена методика управления водными ресурсами в бассейне реки Аса и показатели водозабора, водоснабжения и оценка качества воды. Вода - это экономически важный ресурс, определяющий устойчивость развития страны. Новые тенденции показывают, что водные проблемы становятся все более сложными с другими секторами, включая сельское хозяйство, энергетику, промышленность, транспорт и связь, а также с социальными секторами: образованием, окружающей средой, здравоохранением, развитием сельских районов или регионов. Рациональное использование водных ресурсов, а также охрана водных ресурсов и доступ к питьевой воде являются важным приоритетом для мирового сообщества. Следовательно, в условиях Казахстана, где водные ресурсы ограничены, а орошение развивается в различных природно-климатических зонах, дальнейшая интенсификация орошаемого земледелия может осуществляться путем разработки экологически безопасных интегрированных технологий, эколого-мелиоративного управления водо-земельными ресурсами, обеспечивающих снижение размеров непроизводительных потерь оросительных вод и защиту водо-земельных ресурсов от загрязнения коллекторно-сбросными водами, темпов накопления солей в корнеобитаемом слое и скорости протекания процессов осолонцевания и ощелачивания. Такой подход предопределен тем, что существующие методы управления водными ресурсами, неизбежно приводят к большим потерям оросительных вод на инфильтрацию, сброс и испарение, величина которых достигает $60-70$ \% от водозабора.
\end{abstract}

Ключевые слова: водные ресурсы, водозабор, грунтовые воды, водосберегающая технология, орошение, поверхностные воды.

Цитирование. Аманбаева Б. Ш., Жапаркулова Е. Д., Мустафаев М. Г., Мосиеж Д. Оценка и метод управления водными ресурсами в бассейне реки Аса // Природные системы и ресурсы. - 2021. - Т. 11, № 2. - C. 49-55. - DOI: https://doi.org/10.15688/nsr.jvolsu.2021.2.6

\section{Введение}

В Послании народу Казахстана 30 января 2017 г. Президент Республики Казахстан отметил необходимость технологической модернизации отраслей экономики. В связи с этой задачей Правительством республики принята Государственная программа развития агропромышленного комплекса Республики Казахстан на 2017-2021 гг., направленная на решение актуальных вопросов водного сектора экономики [1].
В контексте экологической ситуации в бассейне реки Аса, нехватки водных ресурсов во время вегетационного периода и возрастающей деградации жилого пространства возникла необходимость в разработке экологически безопасных технологий управления водными ресурсами. Проблема повышения водоснабжения и экологической устойчивости орошаемых экосистем бассейна реки АсаТалас может быть решена за счет использования поверхностных вод. 
Климатическими особенностями местности, в которой расположен бассейн реки Аса, являются резкий температурный контраст, неравномерное распределение осадков, засушливость, высокий уровень солнечной радиации. В южной горной части зимы мягкие и лучше покрываются осадками. Пустынные равнины северных и центральных регионов особенно подвержены засухе.

Решение перечисленных выше проблем необходимо начать прежде всего с изучения динамики водно-физических и химических свойств орошаемых почв, минерализации оросительных и грунтовых вод, их влияние на темпы протекания деградационных процессов в корнеобитаемом слое почв при орошении сельскохозяйственных культур. Поэтому в процессе решения поставленных задач были выполнены полевые, лабораторные исследования по установлению пределов изменения экологомелиоративных процессов при изменении ионно-солевого состава водных ресурсов. При этом комплексность исследований заключалась в том, что одновременно на одних и тех же объектах проводились все виды запланированных исследований по установлению темпов протекания деградационных процессов.

\section{Материал и методы исследования}

Объект исследования расположен в бассейне реки Aca, на орошаемых землях села «Бесагаш». Площадь орошаемых земель составляет 33 тыс. га, для орошения используется вода реки Аса. Река Аса берет свое начало в Кыргызской Республике. Рассматриваемая территория расположена в экосистеме пустыни (см. рисунок).

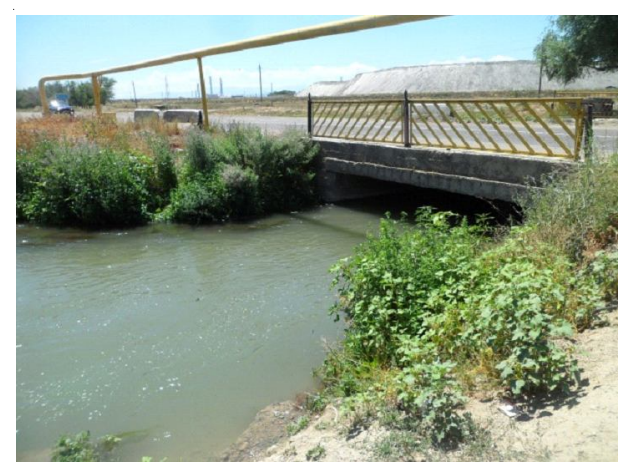

Для оценки качества оросительной воды по опасности осолонцевания применяют натриевое адсорбционное отношение (SAR):

$$
S A R=\frac{N a}{\sqrt{\frac{C a+M g}{2}}} .
$$

При значении SAR менее 10 опасность осолонцевания почв при орошении малая; $\mathrm{SAR}=10-18$ характеризует среднюю опасность; SAR $=18-26$ - высокую; SAR $>26$ - опасность осолонцевания очень высокая.

В оросительных системах Жамбылской области более $90 \%$ орошаемых земель с минерализацией до 3 г/л. Таким образом подземные воды на этой территории могут использоваться для орошения [2; 3]. Значение SAR - (натриеовое адсорбционное отношение) варьируется от 0,46 до 6,17 , что ниже допустимых 10, но местами достигает 18.

Ресурсы поверхностных вод Жамбылской области сосредоточены в бассейнах рек Шу, Талас и Аса, формирование которых практически полностью находится на территории Кыргызской Республики, то есть до $80 \%$ ресурсов поверхностных вод поступает из трансграничных рек соседняя страна. Таким образом, Жамбылская область в период вегетации зависит от соблюдения кыргызской стороной Правил распределения трансграничных рек Шу Талас и Временных правил распределения рек Аспара и Куркиреусу, утвержденных Министерством водного хозяйства СССР в 1983 г., годового стока, составляет 4106 млн грн. м ${ }^{3}$ воды, сток образовался на территории Республики Казахстан - 967,0 млн м ${ }^{3}$ [4].

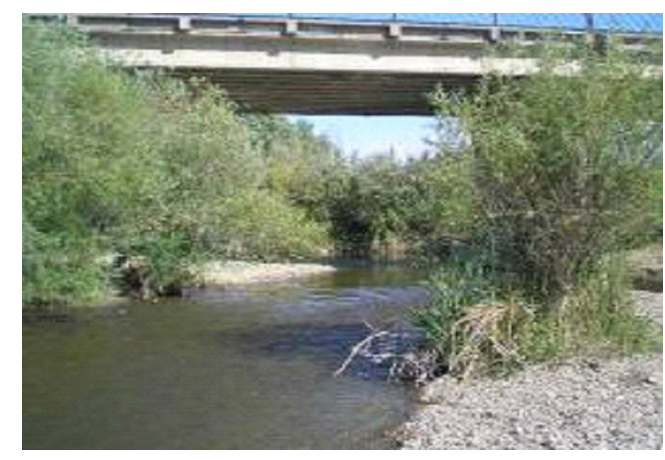

Река Аса в Жамбылской области село «Бесагаш» 
Оценка их качества позволит выявить источники загрязнения и принять меры по снижению их воздействия на экологию орошаемых земель. При орошении необходимо попытаться увеличить малые биологические и сократить большие геологические цепочки, т. е. использовать технологии, позволяющие получить минимальную стоимость воды и минимальную урожайность сельскохозяйственных культур в объеме сброса воды за пределы оросительной системы. Для определения качества воды были отобраны образцы вод из рек Аса, лабораторные исследования проводились в лаборатории Казахского научно-исследовательского института водного хозяйства [5].

Снижение размеров технологических потерь оросительной воды при поливах можно достигнуть при поливах сельскохозяйственных культур через борозду. Технология полива через борозду обеспечивает сокращение потерь оросительной воды на фильтрацию до двух раз, на сброс и испарение до 1,5 раз. За счет снижения этих потерь обеспечивается повышение водообеспеченности орошаемых земель до 20-25\%.

Были проведены полевые опыты в орошаемых землях бассейна реки Аса в селе «Бесагаш». По вариантам: 1. По бороздам (контроль). 2. Поливы через борозду.

\section{Результаты исследований}

Основным источником орошения растений в бассейне реки Аса являются поверхностные воды. Однако в вегетационный период наблюдается ежегодный дефицит поливной воды. По водоснабжению орошаемые земли также находятся на орошаемых землях Жамбылской области (табл. 1). Таким образом, за эти годы водообеспеченность 1 га орошаемых земель в Жамбылской области составила $3561-5988 \mathrm{~m}^{3} /$ га.

Продуктивность орошаемых земель зависит не только от их водоснабжения, но и от качества поливной воды. Результаты исследования показали, что минерализация вод реки Аса увеличивается. В бассейне p. Аса: на p. Терс (Жуалинский район) минерализация воды составляет 0,395 г/л, а в p. Аса (Айшабибинский район, Жамбылский район) - минерализация воды около 4 г/л, в Бирлесу-Енбекском районе (Жамбылский район) - 0,527 г/л (табл. 2).

Преобладающими анионами в верхних потоках являются углеводороды и сульфаты, а катионами - кальций и магний. Соответственно тип засоления - гидрокарбонатно-сульфатно-хлоридная, кальциево-магниево-натриевая [6]. Минерализация воды в озере Акколь пре-

Таблицุа 1

\section{Показатели водопотребления орошаемых земель Жамбылской области}

\begin{tabular}{|c|c|c|c|c|c|}
\hline \multirow[b]{2}{*}{ Годы } & \multirow{2}{*}{$\begin{array}{c}\text { Орошаемые } \\
\text { земли, тыс. га }\end{array}$} & \multirow{2}{*}{$\begin{array}{c}\text { Фактический } \\
\text { полив с учетом } \\
\text { влажности, тыс. га }\end{array}$} & \multicolumn{3}{|c|}{ Водопотребление орошаемого земледелия, млн. м } \\
\hline & & & Водозабор & Водоснабжение & $\begin{array}{c}\text { Поливная норма } \\
\text { (брутто), м³/га }\end{array}$ \\
\hline 2002 & 105,9 & 89,839 & 541,9 & 414,2 & 3913 \\
\hline 2013 & 105,9 & 90294 & 660,1 & 540,7 & 5988 \\
\hline 2014 & 105,9 & 93,854 & 656,1 & 467,1 & 4977 \\
\hline 2015 & 105,9 & 95,963 & 501,7 & 341,7 & 3561 \\
\hline 2016 & 106,0 & 93,046 & 565,5 & 390,8 & 4199 \\
\hline Среднее & 106,0 & 90,539 & 505,8 & 428,6 & 4378 \\
\hline \multicolumn{2}{|c|}{ Коэффициент вариации, \% } & - & 11,53 & 15,77 & - \\
\hline
\end{tabular}

Таблииа 2

Ионный состав воды, подаваемой на орошение из водных источников

\begin{tabular}{|c|c|c|c|c|c|c|c|c|}
\hline \multirow{2}{*}{$\begin{array}{l}\text { Название источни- } \\
\text { ков воды для полива }\end{array}$} & \multicolumn{4}{|c|}{ Анионы } & \multicolumn{3}{|c|}{ Катионы } & \multirow{2}{*}{$\Sigma_{\text {сол. }}, \Gamma / л$} \\
\hline & $\mathrm{CO}_{3}{ }^{2-}$ & $\mathrm{HCO}_{3}^{-}$ & $\mathrm{Cl}^{-}$ & $\mathrm{SO}_{4}{ }^{2-}$ & $\mathrm{Ca}^{2+}$ & $\mathrm{Mg}^{2+}$ & $\mathrm{Na}^{+}$ & \\
\hline $\begin{array}{l}\text { Аса (Бирлесу Ен- } \\
\text { бек) }\end{array}$ & - & $\frac{0,234}{3,84}$ & $\frac{0,037}{1,04}$ & $\frac{0,094}{1,96}$ & $\frac{0,064}{3,20}$ & $\frac{0,019}{1,60}$ & $\frac{0,047}{2,04}$ & 0,495 \\
\hline $\begin{array}{l}\text { Талас (город Тараз, } \\
\text { Автовокзал) }\end{array}$ & $\frac{0,034}{1,12}$ & $\frac{0,171}{2,80}$ & $\frac{0,087}{1,04}$ & $\frac{0,046}{0,96}$ & $\frac{0,060}{3,00}$ & $\frac{0,022}{1,80}$ & $\frac{0,026}{1,12}$ & 0,396 \\
\hline
\end{tabular}

Примечание. Числитель - г/л, знаменатель - мг. экв. 
имущественно сульфатно-бикарбонатно-хлоридно-карбонатная, натриево-магниево-кальциевая.

Что касается общей минерализации, агроэкологическая оценка поверхностных вод в бассейне Асы показала, что они чистые и хорошие (табл. 3).

По показателям K и SAR при использовании этих вод для орошения отсутствует риск засоления почвы, накопление натрия в почвенно-абсорбционном комплексе по SAR* и засоление почвы возможно только при использовании воды из озера Акколь.

Химический состав засоления грунтовых вод Жамбылской области различается гидрокарбонатно-сульфатно-хлоридным, магниевокальциево-натриевым, сульфатно-хлоридногидрокарбонатным.

Защита водных источников от загрязнения должна осуществляться за счет снижения технологических потерь фильтрации и сброса с орошаемых земель и использования подземных вод для орошения при их солености менее 3-4 г/л [7; 8].

В условиях возросшего дефицита водных ресурсов на орошаемых землях Казахстана основным критерием методов экономической оценки поверхностных вод является рациональное использование водных ресурсов. Однако проблема рационального использования воды и земли в сложившихся условиях требует решения путем разработки водосберегающих методов использования поливной воды в оросительных системах.

Результаты исследования поливов по бороздам и через борозду приведены в таблице 4.

По результатом видно расход воды значительно сократился по сравнению с контрольным вариантом.

\section{Заключение}

Разработанная водосберегающая технология по управлению водо-земельными ресурсами обеспечат эколого-мелиоративную стабильность ирригационных систем, путем снижения темпов нарушения природного равновесия. Поэтому при эксплуатации оросительных систем, главное внимание должно уделяться изменению направления общего потока органоминеральных соединений, как в региональном, так и на локальном уровне. Это позволит создать ирригационные системы, способные сохранять полезные для человеческой деятельности природные процессы и органически сочетать их с инженерными сооружениями, играющими роль регуляторов эколого-мелиоративных процессов, обеспечивающие рост продуктивности орошаемых земель. Водосбере-

Оценка качества водных ресурсов в бассейне реки Аса

Таблииа 3

\begin{tabular}{|c|c|c|c|c|c|c|c|c|}
\hline \multirow{2}{*}{$\begin{array}{c}\text { Место } \\
\text { отбора проб }\end{array}$} & \multirow{2}{*}{$\begin{array}{l}\text { Время } \\
\text { отбора } \\
\end{array}$} & \multicolumn{7}{|c|}{ Показатели } \\
\hline & & $\mathrm{C}, \Gamma / \pi$ & $\underline{K}$ & SAR & SAR* & $\mathrm{OKH}$ & $\mathrm{Mg}^{*}$ & $\mathrm{pH}$ \\
\hline \multirow{3}{*}{$\begin{array}{l}\text { Аса } \\
\text { (Айша } \\
\text { бибі) }\end{array}$} & Весна & 0,385 & 10,23 & 0,25 & 0,50 & $-2,00$ & 36,0 & 7,0 \\
\hline & Лето & 0,384 & 5,18 & 0,53 & 1,11 & $-0,80$ & 47,8 & 7,4 \\
\hline & Осень & 0,506 & 5,37 & 0,58 & 1,31 & $-1,80$ & 46,7 & 7,2 \\
\hline \multirow{3}{*}{$\begin{array}{l}\text { Аса } \\
\text { (Аккөл) }\end{array}$} & Весна & 1,103 & 1,30 & 3,23 & 8,03 & $-5,80$ & 68,1 & 7,8 \\
\hline & Лето & 1,191 & 1,74 & 2,66 & 6,83 & $-7,90$ & 75,9 & 8,0 \\
\hline & Осень & 1,347 & 1,09 & 4,23 & 10,57 & $-8,00$ & 85,7 & 8,4 \\
\hline
\end{tabular}

Таблица 4

Использование поливной воды при поливе по бороздам и через борозду в вегетационный период

\begin{tabular}{|l|c|c|c|c|}
\hline \multirow{2}{*}{ Варианты } & Поливная норма & \multicolumn{3}{|c|}{ Расход воды $\left(\mathrm{м}^{3} /\right.$ га) на } \\
\cline { 3 - 5 } & брутто, ${ }^{3} /$ га & Увлажнение почв & Фильтрация & Сброс \\
\hline Полив по & 1500 & 805 & 285 & 260 \\
бороздам & 1100 & 630 & 190 & 180 \\
\hline Полив через & 800 & 496 & 152 & 112 \\
борозду & 600 & 409 & 100 & 60 \\
\hline
\end{tabular}


гающая технология позволят снизят до минимума техногенную нагрузку на природную среду, затраты воды на орошение, сократять непроизводительные потери и инфильрацию.

\section{СПИСОК ЛИТЕРАТУРЫ}

1. Бекбаев, Р. К. Интегрированные методы управления водоземельными ресурсами на ирригационных системах Казахстана / Р. К. Бекбаев // Мелиорация и проблемы восстановления сельского хозяйства России : материалы Междунар. науч.-практ. конф. (Костяковские чтения). - М. : Всероссийский научно-исследовательский институт агрохимии им. Д.Н. Прянишникова, 2013. - С. 26-30.

2. Бекбаев, Р. К. Актуальность водосберегающих технологий орошения на юге Казахстана / Р. К. Бекбаев, Е. С. Койбакова // Научные исследования в мелиорации и водном хозяйстве : сб. науч. тр. - Тараз : КазНИИВХ.-2013.-Т. 50.-С. 55-60.

3. Джаманбаев, Б. С. Выявление ресурсосберегающих инновационных технологий полива. Инновация / Б. С. Джаманбаев // Водное хозяйство Казахстана. - 2013. - Т. 4, № 54. - С. 27-32.

4. Жапаркулова, Е. Д. Аса-Талас өзендері алабындағы суғармалы жерлердін экологиялық жағдайы мен оларды сумен қамтамасыз ету мәселелері / Е. Д. Жапаркулова, Р. А. Жайсамбекова // М.Х. Дулати атындағы «ТарМУ Жаршысы». - 2010. - № 4. - С. 18-23.

5. Магай, С. Д. Орошаемое земледелие в Казахстане и за рубежом / С. Д. Магай, Р. Г. Мирсаитов // Научные исследования в мелиорации и водном хозяйстве : сб. науч. тр. - Тараз : ТОО «КазНИИВХ».-2013. - Т. 50. - С. 65-70.

6. Technology of Improve the Fertility of Degraded Irrigated Land in Southern Kazakhstan / R.K. Bekbayev [et al.] // European Science and Technology. Materials of the IV International Research and Practice Conference. - 2013. - Vol. I. - P. 405-408.

7. Vyshpolsky, F. F. Influence of the Technical Condition of Irrigation Systems on the Size of Irrigation Norms / F. F. Vyshpolsky, E. D. Zhaparkulova, U. K. Bekbayev // Aplikovane vědeckě novinky-2013 : materiály IX mezinárodní vědecko-praktická conference. Díl 11, Ekologie, Zemepis a geologie, Zemědělstvi, Zvěrolekarstvi. - Praha : Education and Science, 2013. - P. 27-31.

8. Zhaparkulova, E. D. Priority Technological Operations for Reconstruction of Irrigation Systems / E. D. Zhaparkulova, E. S. Koibakova // European Science and Technology. Materials of the IV International Research and Practice Conference. 2013. - Vol. I. - P. 405-408.

\section{REFERENCES}

1. Bekbaev R.K. Integrirovannye metody upravleniia vodozemelnymi resursami na irrigatsionnykh sistemakh Kazakhstana [Integrated Management Methods for Water and Land Resources on Irrigation Systems in Kazakhstan]. Melioratsiia i problemy vosstanovleniia selskogo khoziaistva Rossii. materialy Mezhdunarodnoi nauchno-prakticheskoi konferentsii (Kostiakovskie chteniia) [Melioration and problems of restoration of agriculture in Russia. Materials of the International Scientific and Practical Conference (Kostyakov Readings)]. Moscow, Pryanishnikov Institute of Agrochemistry, 2013, pp. 26-30.

2. Bekbaev R.K., Koibakova E.S. Aktual'nost' vodosberegayushchikh tekhnologiy orosheniya na yuge Kazakhstana [Relevance of Water-Saving Irrigation Technologies in the South of Kazakhstan]. Nauchnye issledovaniya $v$ melioratsii $i$ vodnom khozyaystve : sb. nauch. tr. [Scientific Research in Land Reclamation and Water Management: Collection of Scientific Papers]. Taraz, KazSRIWE, 2013, vol. 50, pp. $55-60$.

3. Dzhamanbaev B.S. Vyyavlenie resursosberegayushchikh innovatsionnykh tekhnologiy poliva. Innovatsiya [Revealing Resource-Saving Innovative Irrigation Technologies. Innovation]. Nauchno-informatsionnyy zhurnal "Vodnoe khozyaystvo Kazakhstana» [Scientific and Information Journal "Water Economy of Kazakhstan”], 2013, vol. 4, no. 54, pp. 27-32.

4. Zhaparkulova E.D., Zhaisambekova R.A. Ecological Condition of Irrigated Lands in the Basin of Asa-Talas Rivers and Problems of Their Water Supply. Bulletin of TarSU Named After Dulati, 2010, no. 4, pp. 18-23.

5. Magai S.D., Mirsaitov R.G. Oroshaemoe zemledelie v Kazakhstane i za rubezhom [Irrigated Agriculture in Kazakhstan and Abroad]. Nauchnye issledovaniya $v$ melioratsii $i$ vodnom khozyaystve : sb. nauch. tr. [Scientific Research in Land Reclamation and Water Management: Collection of Scientific Papers]. Taraz, KazSRIWE, 2013, vol. 50, pp. 65-70.

6. Bekbayev R.K., Balgabayev N.N., Zhaparkulova E.D., Bekbayev U.K. Technology of Improve the Fertility of Degraded Irrigated Land in Southern Kazakhstan. European Science and Technology. Materials of the $4^{\text {th }}$ International Research and Practice Conference, 2013, vol. I, pp. 405-408.

7. Vyshpolsky F.F., Zhaparkulova E.D., Bekbayev U.K. Influence of the Technical Condition 
of Irrigation Systems on the Size of Irrigation Norms. Materials of the $4^{\text {th }}$ International Scientific Practical Conference "Applied Scientific News 2013». - Part 11, Ecology, Geography and Geology, Agriculture, Veterinary Medicine. Prague, Education and Science Publ., 2013, pp. 27-31.
8. Zhaparkulova E.D., Koibakova E.S. Priority Technological Operations for Reconstruction of Irrigation Systems. European Science and Technology. Materials of the IV International Research and Practice Conference, 2013, vol. I, pp. 405-408.

\section{Information About the Authors}

Balzhan Sh. Amanbaeva, PhD Doctoral Student, Specialty by "Water Resources and Water Usage" at Department "Water Resources and Reclamation" at Kazakh National Agrarian Research University, Prosp.Abay, 8, 050010 Almaty, Kazakhstan, amanbaeva88@mail.ru

Ermekkul D. Zhaparkulova, Candidate of Sciences (Agriculture), Professor, Department "Water Resources and Reclamation”, Kazakh National Agrarian Research University, Prosp. Abay, 8, 050010 Almaty, Kazakhstan, ermekull@mail.ru

Mustafa G. Mustafayev, Doctor of Sciences (Agriculture), Academian, Academy Russian Natural Science, Head of Department Institute of Soil Science and Agrochemistry of Azerbaijan National Academy of Science, M. Ragima St, 5, AZ10073 Baku, Azerbaijan, meliorasiya58@mail.ru

Josef Mosiej, Doctor of Sciences (Agriculture), Professor, Warsaw University of Life Sciences SGGW, Novoyrsinovka St, 166, 02-787 Warsaw, Poland, jozef_mosiej@sggw.pl

\section{Информация об авторах}

Балжан Шакировна Аманбаева, $\mathrm{PhD}$-докторант специальности «Водные ресурсы и водопользование» кафедры «Водные ресурсы и мелиорация», Казахский Национальный Аграрный Исследовательский Университет, просп. Абая, 8, 050010 г. Алматы, Казахстан, amanbaeva88@mail.ru

Ермеккуль Дукеновна Жапаркулова, кандидат сельскохозяйственных наук, профессор кафедры «Водные ресурсы и мелиорация», Казахский Национальный Аграрный Исследовательский Университет, просп. Абая, 8, 050010 г. Алматы, Казахстан, ermekull@mail.ru

Мустафа Гылман Мустафаев, доктор сельскохозяйственных наук, академик Российской Академии Естествознания, заведующий лабораторией мелиорации почв, Институт почвоведения и агрохимии НАН Азербайджана, ул. М. Рагима, 5, AZ10073 г. Баку, Азербайджан, meliorasiya58@mail.ru

Джозеф Мосиеж, доктор сельскохозяйственных наук, профессор, Варшавский университет естественных наук, ул. Новоурсуновка, 166, 02-787 г. Варшава, Польша, jozef_mosiej@sggw.pl 